\title{
The Optimum Thermal Environment for Naked Babies
}

\author{
E. N. HEY and G. KATZ \\ From the Neonatal Research Group, The London Hospital Medical College, London
}

\begin{abstract}
Hey, E. N., and Katz, G. (1970). Archives of Disease in Childhood, 45, 328. The optimum thermal environment for naked babies. The optimum thermal environment in which to nurse a baby naked in an incubator has been defined from a knowledge of the magnitude of the factors affecting thermal balance.

Such a neutral environment allows body temperature to remain normal while oxygen consumption and evaporative water loss are both at a minimum.
\end{abstract}

A considerable amount of attention has been paid to the need to provide adequate warmth for babies being nursed naked in incubators, but estimates of what constitutes an ideal environmental temperature have varied a good deal. Several attempts have been made to define an optimum minimum temperature, but no study has been made of safe maximum temperature, though without this information the rational selection of incubator temperature is extremely difficult. Considerable difficulty has also been encountered in equating the environmental conditions provided by an experimental metabolism chamber with those provided by an incubator, because the stipulation of air temperature is not by itself enough to define optimal conditions: the separate contributions of heat loss by conduction, convection, radiation, and evaporation need first to be assessed.

In the present paper we have drawn together the results obtained in a number of recently published studies in an attempt to define what constitutes a neutral thermal environment for a naked baby in a commercial incubator. A neutral thermal environment makes minimal demands on the subject's energy reserves, body temperature being regulated by changes in skin blood flow, posture, and sweating: the term may be used to describe any set of conditions which allows body temperature to remain normal while oxygen consumption and heat production are minimal and effectively matched by heat loss. A rather narrower definition, which seems more appropriate for the present purpose, would also exclude conditions that provoke active sweating.

Received 20 November 1969.
Whether this environment is strictly the optimum environment in which to nurse the naked baby is $\complement$ open to question. There can be little doubt, $\underset{\vec{D}}{\vec{D}}$ however, that it approximates quite closely to the $\overrightarrow{\overrightarrow{0}}$ optimum. Babies become restless and their body temperature rises significantly above normal if . environmental temperature exceeds the neutral range, while several controlled trials have shown that mortality rises if small infants are nursed in $\overline{0}$ surroundings more than a degree or two below the neutral temperature range.

\section{Methods}

The data on heat production and heat loss on which the present analysis is based were obtained using a specially constructed metabolic chamber at The London Hospital. 123 healthy premature and full-term infants of known gestation have been studied with the consent of their parents. Many of the smaller infants were studied at least twice a week throughout the first month of life. The babies weighed between 0.96 and $4.76 \mathrm{~kg}$. at birth. We have studied the range of control that these naked babies exerted over evaporative and nonevaporative heat loss, and measured average heat production while the babies lay at rest in warm surroundings free of thermal stress. We have then combined $N$ these findings in order to establish estimates of what constitutes a neutral thermal environment.

Heat production was calculated from measured oxygen consumption on the assumption that the consumption of 1 litre of $\mathrm{O}_{2}$ at S.T.P. (dry) liberates 4.83 kilocalories of heat. Evaporative heat loss was calculated from measured water loss on the assumption that the evaporation of $1 \mathrm{~g}$. water results in the loss of 0.6 kilocalories of heat from the body. Estimates of nonevaporative heat loss were obtained indirectly from measurements of heat production and heat storage, 


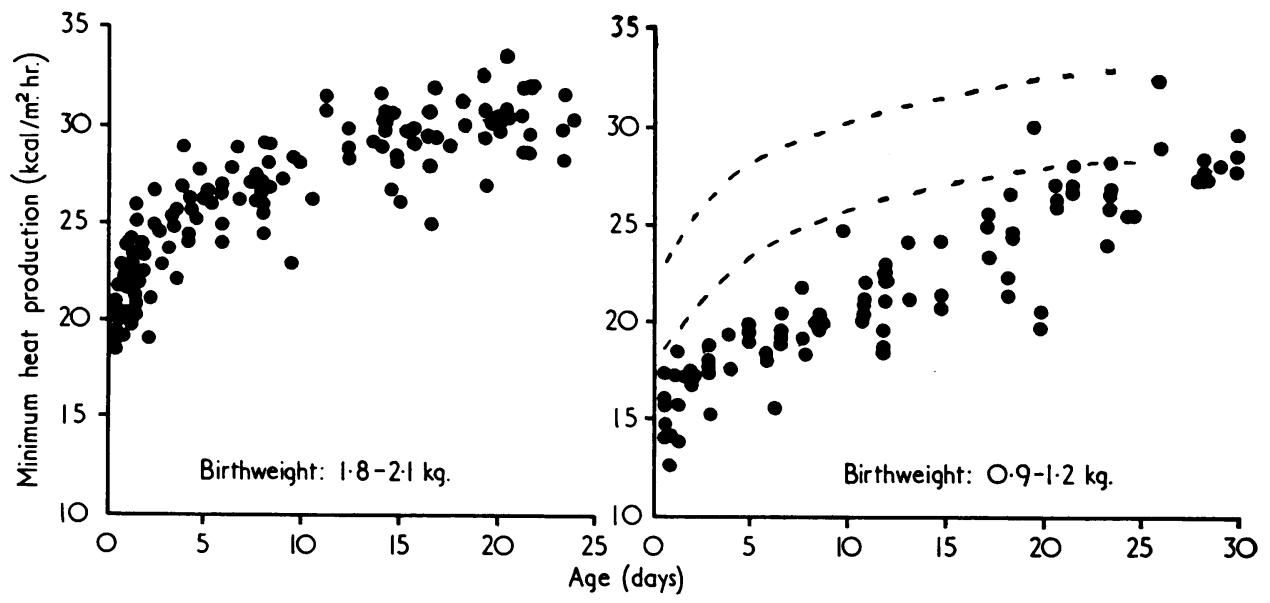

Fig. 1.-Heat production in a warm environment during the first weeks of life. Heat production per unit surface area is particularly low in small babies in the first two weeks of life.

after subtraction of the evaporative heat loss. Full details of the methods employed will be found in the papers published in the Journal of Physiology (Hey, 1969; Hey and Katz, 1969, 1970; Hey, Katz, and O'Connell, 1970).

Air speed in the experimental chamber was 4-5 $\mathrm{cm}$./sec., which is similar to the speed found above the mattress in most commercial incubators (Hey and Mount, 1967; Bardell, Freeman, and Hey, 1968). Water vapour pressure was kept constant at between 17 and $19 \mathrm{~mm} . \mathrm{Hg}$ in the main series of tests, so that the relative humidity in the metabolic chamber was approximately $50 \%$ when the temperature was between 30 and $35^{\circ} \mathrm{C}$. The difference between the measured conductive heat loss in the metabolic chamber and the expected loss in an incubator was allowed for in the assessment of non-evaporative heat loss. The mean radiant temperature of the surrounding surfaces was not allowed to deviate by more than $1^{\circ} \mathrm{C}$. from mean air temperature, and operative environmental temperature was estimated by taking a weighted average of the mean air and mean radiant temperatures. The operative temperature in fact combines in a single variable the temperature equivalent of both the radiant and the convective environments (Gagge, 1940, Equation 5).

\section{Data}

Heat production in an environment free of thermal stress. Heat production has been measured in more than a hundred naked babies. Measurements were obtained at five or more environmental temperatures on each occasion in order to determine what temperature within the metabolism chamber was associated with minimum heat production. At high environmental temperature heat production remained low at first, but rectal temperature rose rapidly. At low environmental temperature heat production increased in every baby and rectal temperature nearly always fell to some extent. Between these extremes lay an environmental temperature associated with minimal thermal stress, in which rectal temperature was between 36.5 and $37.5^{\circ} \mathrm{C}$. and remained constant or only rose slowly $\left(<0.4^{\circ} \mathrm{C}\right.$. $/ \mathrm{hr}$. $)$ and in which heat production was not detectably increased by cold stress.

Heat production per unit surface area in an environment free of thermal stress has been found to increase with postnatal age. In babies weighing more than $2 \mathrm{~kg}$. at birth, the increase occurs most rapidly in the first 5 days of life; in babies weighing less than this heat production per unit surface area is significantly lower during the first 2 weeks of life, and only rises gradually to the levels found in heavier babies (Fig. 1). All the babies included in this study who were more than 1 day old were being fed every 3 or 4 hours. The estimates of average heat production given here automatically include an allowance, therefore, for the specific dynamic action of the food ingested (Murlin, Conklin, and Marsh, 1925; Mestyán et al., 1969). The resultant estimates are a little higher than, but closely related to, the values for basal energy metabolism established by previous workers (cf. Hill and Robinson, 1968). The differences are probably due to the fact that the present estimates represent average heat production over a period of at least half an hour; though the babies were quiet for most of the time they were not necessarily asleep, and many of them showed brief intermittent activity.

Evaporative heat loss. Minimum evaporative heat loss from the skin and respiratory tract has been measured in a similar group of babies and has 
been found to be related to basal metabolic rate. Basal evaporative heat loss usually accounted for about a quarter of minimum heat production, but evaporative heat loss was, of course, influenced by the humidity of the surroundings. Basal evaporative heat loss accounted for as much as $30 \%$ of minimum heat production in a neutral thermal environment if the air was $25 \%$ saturated, whereas it accounted for only $19 \%$ of minimum heat production when the air was $75 \%$ saturated.

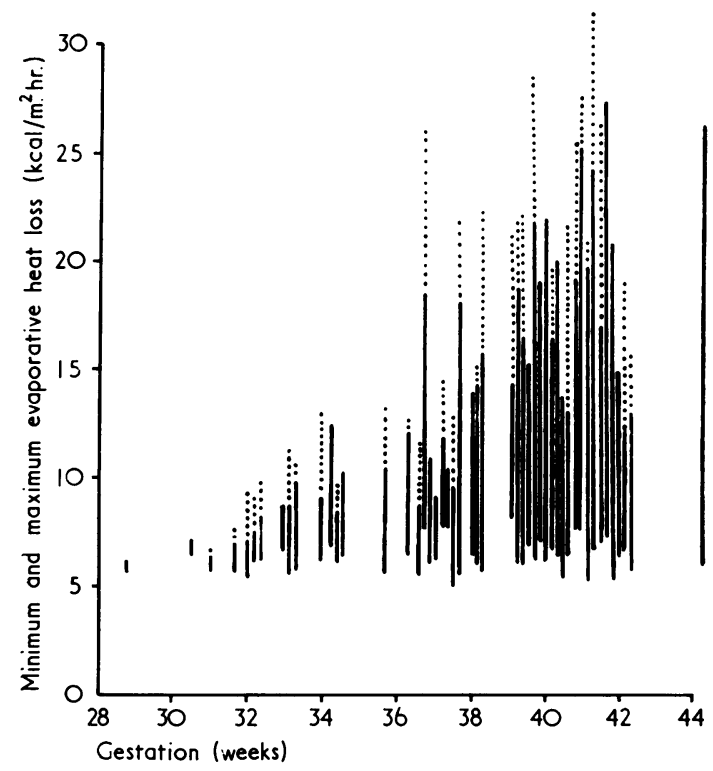

FIG. 2.-Minimum and maximum evaporative heat loss during the first 10 days of life. Lines link the minimum recorded loss in 49 babies with the maximum loss when rectal temperature was $37.5^{\circ} \mathrm{C}$, and the dotted extension shows the further increase in evaporative loss observed when rectal temperature rose to $37 \cdot 8^{\circ} \mathrm{C}$. (100 ${ }^{\circ} \mathrm{F}$.).

These direct estimates of the effect of humidity on heat balance are in good accord with other more indirect estimates (Hey and Maurice, 1968), and the range of humidity studied is reasonably close to the range of humidity obtainable in many commercial incubators (Bardell et al., 1968).

Mature babies sweat in a hot environment when rectal temperature rises above about $37 \cdot 2{ }^{\circ} \mathrm{C}$., but the resultant increase in evaporative heat loss is often limited. The ability of each baby to control its body temperature by increasing its evaporative heat loss was tested in the experimental metabolism chamber in an environment of 36$37^{\circ} \mathrm{C}$. Under these conditions rectal temperature rose slowly in every baby. Fig. 2 summarizes the results obtained in 49 babies of varying maturity when studied 2-10 days after birth. Evaporative heat loss increased two- to fourfold in babies $\overrightarrow{\vec{F}}$ born within 3 weeks of term when rectal temperature rose above $37.5^{\circ} \mathrm{C}$., but very few babies were able to lose by evaporation all the heat they were $\frac{\bar{c}}{\omega}$. producing under basal conditions, even when body $\frac{\bar{\sigma}}{\overrightarrow{0}}$ temperature was as high as $37 \cdot 8^{\circ} \mathrm{C}$. $\left(100^{\circ} \mathrm{F}\right.$.). $\varrho$

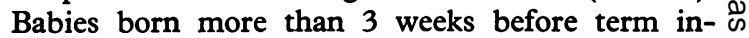
creased their evaporative heat loss even less in a $\overrightarrow{0}$ hot environment, while babies born more than $8 \overrightarrow{\vec{H}}$ weeks before term seemed unable to increase their $\vec{\omega}$ evaporative heat loss at all. These differences have been shown to be related to the functional immaturity of the eccrine sweat glands (Foster, $\frac{i}{\mathrm{r}}$ Hey, and Katz, 1969).

Non-evaporative heat loss. Heat loss due to radiation and convection is inversely related to the environmental temperature, and falls to nothing when the environmental temperature is the same as body temperature. The results summarized in Fig. 3 show the relation found in 12 babies weighing approximately $2 \mathrm{~kg}$. and $2-10$ days old when $\vec{\varphi}$ studied in a draught-free environment in which $\supset$ natural convection currents account for almost all the measured air movement $(4-5 \mathrm{~cm}$. $/ \mathrm{sec}$.). The average minimum heat loss was $5.5 \mathrm{kcal} . / \mathrm{m} .{ }^{2} \mathrm{hr}$. ${ }^{\circ} \mathrm{C}$. A similar relation was found in all the babies studied, but in the smallest babies the minimum radiant and convective heat loss was higher and averaged $6.7 \mathrm{kcal} . / \mathrm{m} .{ }^{2} \mathrm{hr} .{ }^{\circ} \mathrm{C}$. This difference is an index of the lower total specific thermal insulation of the smaller babies.

If the body were an inanimate source of heat it would be possible to describe the results obtained by a simple linear relation. This is not quite the case because babies vasodilate in a warm environment when body temperature is sufficiently high and lose heat more readily. The deviation from linearity is illustrated in Fig. 3. The results are perhaps better expressed by two separate lines indicating the minimum and maximum rates at which a baby can lose heat by convection and radiation. Maximum non-evaporative heat loss is about $6.7 \mathrm{kcal} . / \mathrm{m} .{ }^{2} \mathrm{hr} .{ }^{\circ} \mathrm{C}$. in a $2 \mathrm{~kg}$. baby and about $7.8 \mathrm{kcal} . / \mathrm{m} .{ }^{2} \mathrm{hr} .{ }^{\circ} \mathrm{C}$. in a baby weighing $1 \mathrm{~kg}$.

Conductive heat loss by contact with the mattress is a further potential source of non-evaporative heat loss, but, because of the insulating properties of the mattress material and the small temperature gradient, conductive heat exchange is small in most incubators: indeed where the heater is immediately below the mattress the temperature of the base-plate is usually more than $37^{\circ} \mathrm{C}$. (Hey and Mount, 1967) 


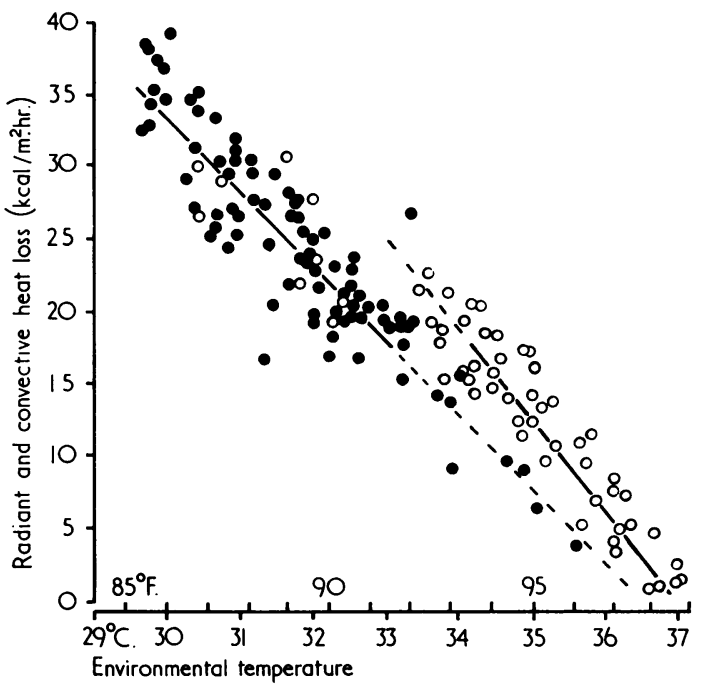

FIG. 3.-Heat loss by radiation and convection in 12 babies weighing approximately $2 \mathrm{~kg}$. at birth. The solid lines indicate the best linear relations for the data obtained in an environment of $28-33^{\circ} \mathrm{C}$. with rectal temperature $<37.2^{\circ} \mathrm{C}$. and in an environment of $34-37^{\circ} \mathrm{C}$. with rectal temperature $\geq 37 \cdot 2^{\circ} \mathrm{C}$. (All the results obtained when rectal temperature was $37 \cdot 2^{\circ} \mathrm{C}$. or more are indicated by open symbols.) Heat loss per unit temperature gradient is greater, because of vasodilatation, in a warm environment when rectal temperature is high.

and the baby gains between 0.05 and 0.3 kilocalories of heat per hour. Conductive exchange in an incubator normally, therefore, accounts for less than $5 \%$ of basal heat production, and since the latter is in any case so variable (Fig. 1), conductive exchange can be largely ignored in the calculations involving over-all thermal balance.

\section{Deductions}

Assessment of neutral operative temperature. If we combine the information about the range of control that can be achieved over nonevaporative heat loss with the data on evaporative heat loss and average heat production in an environment free of thermal stress, it is now possible to define the neutral thermal environment for naked babies lying on a warm mattress in a draught-frcc environment with reasonable accuracy.

For example, the data show that a baby weighing $1 \mathrm{~kg}$. at birth produces about $18 \mathrm{kcal} . / \mathrm{m}^{2}$ of heat $\mathrm{pcr}$ hour in a warm environment free of thermal stress when 2 days old (Fig. 1), and dissipates a minimum of about $4.5 \mathrm{kcal} . / \mathrm{m}{ }^{2}$ per hour by insensible perspiration when the air is $50 \%$ saturated. When the baby is in thermal balance the remaining $13.5 \mathrm{kcal} . / \mathrm{m} .^{2} \mathrm{hr}$. must be lost by convection and radiation if the conductive exchange is small enough to be ignored. When naked and vasoconstricted, such a baby in fact loses about $6.7 \mathrm{kcal} . / \mathrm{m} .{ }^{2} \mathrm{hr}$. in this way for every degree by which deep body temperature exceeds the mean temperature of the air and surrounding surfaces. * It follows therefore, that, if the surroundings fall more than $13 \cdot 5 / 6 \cdot 7$ or about $2{ }^{\circ} \mathrm{C}$. below deep body temperature, a 2-day-old $1 \mathrm{~kg}$. baby will only be able to maintain its deep body temperature constant if heat production rises.

From calculations of this nature it is possible to calculate accurately both the minimum and the maximum environmental temperature to provide conditions of thermal neutrality for any baby being nursed naked in a commercial incubator. The normal range of operative temperature to provide strict thermal neutrality during the first month of life is summarized diagrammatically in Fig. 4 for babies weighing $1 \mathrm{~kg}$. and $2 \mathrm{~kg}$. at birth. The equivalent temperature for a baby weighing $3 \mathrm{~kg}$. at birth falls from about $34^{\circ} \mathrm{C}$. on the day of birth to between 32 and $33^{\circ} \mathrm{C}$. within a couple of days, and thereafter changes very slowly. The neutral

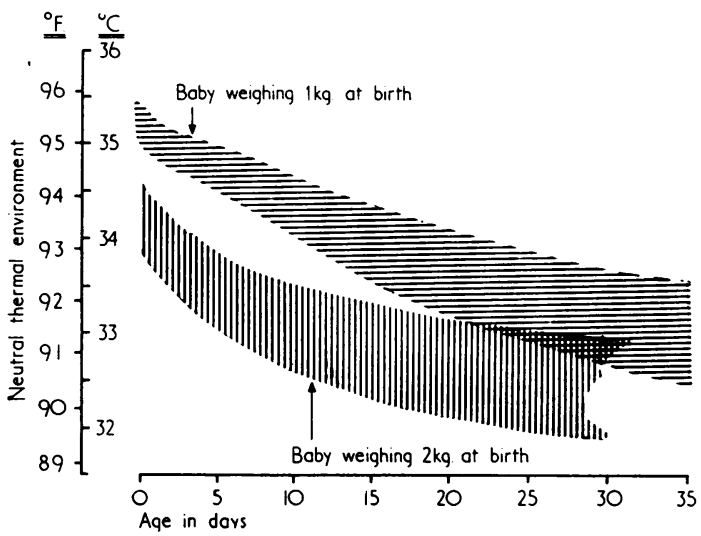

FIG. 4.-The range of temperature to provide neutral environmental conditions for a baby lying naked on a warm mattress in draught-free surroundings of moderate humidity (50\% sat.) when mean radiant temperature is the same as air temperature. The hatched area shows the average neutral temperature range for a healthy baby weighing $1 \mathrm{~kg}$. (三) or $2 \mathrm{~kg}$. (IIII) at birth. 'Optimum' temperature probably approximates to the lower limit of the neutral range as defined here. Approximately $1^{\circ} \mathrm{C}$. should be added to these operative temperatures in order to derive the appropriate neutral air temperature for a single-walled incubator when room temperature is less than $27^{\circ} \mathrm{C}$. $\left(80^{\circ} \mathrm{F}.\right)$, and rather more if room temperature is very much less than this.

ॠThis is a slight simplification. See Hey et al. (1970). 
operative temperature for a baby weighing $4 \mathrm{~kg}$. or more at birth is about half a degree lower than that for a baby weighing $3 \mathrm{~kg}$.

These are average results for healthy babies when the air is $50 \%$ saturated with water vapour and the rectal temperature is between 36.8 and $37.2{ }^{\circ} \mathrm{C}$. Increasing the relative humidity from $25 \%$ to $75 \%$ decreases both the minimum and maximum calculated neutral temperature by about half a degree. It should be noted that all these results are expressed in terms of operative temperature; this is seldom the same as temperature recorded by the thermometer provided in most single-walled commercial incubators (see below).

\section{Comment}

The neutral environmental temperature is high throughout the first month of life, and the range of temperature to provide conditions of complete neutrality is small. Estimates published by previous authors have varied quite widely (see Hill and Rahimtulla, 1965; Scopes and Ahmed, 1966; and a number of earlier studies referred to in these papers). The estimates given in Fig. 4 differ significantly from some of those previously published, but most of the earlier studies were based entirely on the measurement of oxygen consumption in experiments of short duration; a true thermal equilibrium was never achieved, and the exact nature of the thermal environment was incompletely defined. It has hitherto proved difficult, therefore, to allow for the subtle difference between the environment provided by an incubator and that provided by an experimental metabolism chamber.

Importance of environmental warmth. It still seems to be widely assumed that there can be little at fault with the environmental conditions in which a baby is being nursed as long as rectal temperature remains relatively normal. This is to underestimate the importance of the normal physiological control mechanisms and the effectiveness of a baby's ability to deal with thermal stress. Most babies can maintain a reasonably normal rectal temperature in the face of quite marked cold stress; rectal temperature only falls markedly when the stress is so intense as to overwhelm the normal physiological response to this stress.

If the environmental temperature exceeds the neutral range a considerable increase in rectal temperature will occur. The increase will be particularly marked in those babies of short gestation who are most likely to require incubator care, because these babies do not sweat very effectively (Fig. 2). If, on the other hand, the environmental temperature falls below the neutral range, the effect on rectal temperature will normally be small, because most babies will compensate by generating more heat, but oxygen and calorie requirements will of course rise. A fall in environmental temperature of $2{ }^{\circ} \mathrm{C}$. will cause heat production in many babies to rise more than $25 \%$.

Though most babies can cope with lower temperatures up to a point, a situation is soon reached in which the survival of some small infants is in jeopardy. Two controlled trials gave quite clearcut results in 1964 (Buetow and Klein, 1964; Day et al., 1964). Groups of babies weighing less than $1.5 \mathrm{~kg}$. were nursed in conventional incubators with high humidity and an air temperature of $31.5{ }^{\circ} \mathrm{C}$. $\left(89^{\circ} \mathrm{F}\right.$.). Those who also had extra radiant heat provided to maintain the abdominal skin at $36^{\circ} \mathrm{C}$. survived significantly more often than those provided with no extra radiant warmth.

Body temperature is frequently less than $36^{\circ} \mathrm{C}$. throughout the first week of life in tiny babies receiving conventional nursing care, and this is not always associated with any sustained increase in heat production (Brück, Parmelee, and Brück, 1962; Silverman and Agate, 1964). It has often been suggested that such a situation is 'normal', and on this basis it could be argued that these babies are still in a neutral thermal environment. However, it must be pointed out that mortality was reduced by keeping deep body temperature above $36^{\circ} \mathrm{C}$. in the controlled trials already referred to.

An environment that provides neutral thermal conditions is recognizable to an adult because it feels pleasantly comfortable, and Brück et al. (1962) produced some indirect evidence to suggest that this may also be true for the human baby. Newborn pigs if given the chance, however, choose an environment a little below that which provides strict thermal neutrality (Mount, 1963), and it may not be irrelevant to comment that, though the newborn pig is more mobile than the human infant at birth, it is like the premature baby in its inability to protect itself from hyperthermia by sweating.

Some of the clinical consequences of nursing small babies naked in a neutral thermal environment have recently been examined by Glass, Silverman, and Sinclair (1968), while Brück (1968) in a commentary has broached the problem of the equivalence of the neutral and the 'optimal' thermal environments more formally. While much remains to be learnt about this problem, there can be little doubt that small babies should be nursed in a warmer environment than has been common in the fairly recent past. The neutral range is, nevertheless, small and the baby's ability to control 
its temperature particularly inadequate when environmental temperature exceeds this range. Apnoeic attacks are also more frequent when small babies are nursed in an environment adjusted to maintain abdominal skin temperature at $36 \cdot 8^{\circ} \mathrm{C}$. rather than $36.0^{\circ} \mathrm{C}$. (Daily, Klaus, and Meyer, 1969). It seems, therefore, that the lower limit of the neutral range is the most logical temperature to aim for in clinical practice. In most of the small babies we studied such an environment produced an equilibrium abdominal skin temperature that was close to $36.4{ }^{\circ} \mathrm{C}$., but in the babies that weighed over $2 \mathrm{~kg}$. the abdominal temperature was usually nearer $36 \cdot 2^{\circ} \mathrm{C}$.

Management of incubator temperature. It cannot be stressed too strongly that the temperatures in Fig. 4 are operative temperatures. In most commercial incubators the surfaces are cooler than the air surrounding the baby, and mean radiant temperature is consequently less than air temperature. Under these circumstances the operative temperature is less than the temperature recorded by the thermometer inside the incubator. Hey and Mount (1967) were able to show that the magnitude of this effect could be predicted if room temperature was known; they concluded that operative temperature within most incubators fell one degree below incubator air temperature for every seven degrees by which incubator air temperature exceeded room temperature.

As a rough working rule, therefore, one degree Centigrade should be added to all the temperatures given in Fig. 4 when estimating 'neutral' air temperature in a single-walled incubator if room temperature is less than $27^{\circ} \mathrm{C}$. $\left(80^{\circ} \mathrm{F}\right.$.). When this is done the estimates for the lower limit of the neutral environment are found to agree quite closely with the conclusions about optimum incubator air temperature reached by a number of clinicians on empirical grounds (cf. Oliver, 1965).

It must also be remembered, however, that these results refer to normal, apparently healthy babies. While little variation has been observed in basal evaporative and non-evaporative heat loss (Fig. 2 and 3), considerable variation has been encountered in the amount of heat produced in a neutral environment (Fig. 1), and this variation is exaggerated by disease. Heat production is reduced in many ill babies, but is occasionally increased in babies with cerebral damage even in the absence of overt restlessness, and it may be advisable to adjust the environmental conditions to allow for this variation.

There are some practical advantages in controlling incubator warmth by means of a sensing thermistor strapped to the baby's abdomen (Agate and Silverman, 1963), but such equipment adds to the complexity and cost of any incubator and deprives the temperature chart of its clinical value. Experience suggests that there is also a risk of hyperthermia as a result of drift in the setting with some currently available control equipment. In the light of the information about heat balance in the newborn baby now available, it ought to be possible to prescribe an equally satisfactory environment using any incubator presently manufactured. Various modifications in design would help to make this ideal easier to achieve in practice: the main requirement for any incubator should be the ability to provide and maintain any selected operative temperature between 30 and $35^{\circ} \mathrm{C}$. to an accuracy of within half a degree.

In order to minimize the risk of hyperthermia, British Standard 3061 (1965) requires that incubators shall be so designed that air temperature does not exceed $35^{\circ} \mathrm{C}$. In these circumstances a number of tiny babies continue to suffer cold stress when nursed in the most modern and expensive equipment unless a high room temperature is maintained. It is in fact quite impossible to find a single safe maximum temperature for incubators. The minimum temperature to provide a neutral environment for a $1 \mathrm{~kg}$. baby usually exceeds the maximum safe temperature for a $2 \mathrm{~kg}$. baby throughout the first two weeks of life (Fig. 4). Any incubator designed to provide a neutral environment for a $1 \mathrm{~kg}$. infant on the day of birth will inevitably expose the same infant, when older, to the risk of hyperthermia if the control thermostat is turned full on.

We are grateful to Professor K. W. Cross for encouragement and advice, and wish to acknowledge the skill and help of Miss Elizabeth Bardell, S.R.N., S.C.M., and Mrs. Jill Freeman, S.R.N., R.S.C.N., with the studies upon which this analysis is based. We wish to thank the parents, and the paediatric, obstetric, and nursing staff of The London Hospital, without whose interest and help this work would not have been possible.

This work was begun with support from the Medical Research Council in their Research Group on Respiration and Energy Metabolism in the Newborn. Responsibility for the Group and for subsequent work was assumed by The London Hospital Medical College on 1 August 1967.

REFERENCES

Agate, F. J., Jr., and Silverman, W. A. (1963). The control of body temperature in the small newborn infant by low-energy infrared radiation. Pediatrics, 31, 725 .

Bardell, E., Freeman, J., and Hey, E. N. (1968). Relative humidity in incubators. Archives of Disease in Childhood, 43, 172.

British Standard 3061 (1965). Specification for Electrically-Heated Incubators for Babies. British Standards Institution, London.

Brück, K. (1968). Which environmental temperature does the premature infant prefer? Pediatrics, 41, 1027.

Parmelee, A. H., Jr., and Brück, M. (1962). Neutral temperature range and range of 'thermal comfort' in premature infants. Biologia Neonatorum, 4, 32. 
Buetow, K. C., and Klein, S. W. (1964). Effect of maintenance of 'normal' skin temperature on survival of infants of low birth weight. Pediatrics, 34, 163.

Daily, W. J. R., Klaus, M. and Meyer, H. B. P. (1969). Apnea in premature infants: monitoring, incidence, heart rate changes, and an effect of enviromental temperature. Pediatrics, 43, 510 .

Day, R. L., Caliguiri, L., Kamenski, C., and Ehrlich, F. (1964). Body temperature and survival of premature infants. Pediatrics, 34, 171.

Foster, K. G., Hey, E. N., and Katz, G. (1969). The response of the sweat glands of the new-born baby to thermal stimuli and to intradermal acetylcholine. Fournal of Physiology, 203, 13.

Gagge, A. P. (1940). Standard operative temperature, a generalized temperature scale, applicable to direct and partitional calorimetry. American fournal of Physiology, 131, 93.

Glass, L., Silverman, W. A., and Sinclair, J. C. (1968). Effect of the thermal environment on cold resistance and growth of small infants after the first week of life. Pediatrics, 41, 1033.

Hey, E. N. (1969). The relation between environmental temperature and oxygen consumption in the new-born baby. Fournal of Physiology, 200, 589.

- and Katz, G. (1969). Evaporative water loss in the new-born baby. Fournal of Physiology, 200, 605.

- and - (1970). The range of thermal insulation in the tissues of the new-born baby. Fournal of Physiology, 207, 667.

,-- , and O'Connell, B. (1970). The total thermal insulation of the new-born baby. Fournal of Physiology, 207, 683.

, and Maurice, N. P. (1968). Effect of humidity on production and loss of heat in the newborn baby. Archives of Disease in Childhood, 43, 166. $\longrightarrow$, and Mount, L. E. (1967). Heat losses from babies in incubators. Archives of Disease in Childhood, 42, 75.

Hill, J. R., and Rahimtulla, K. A. (1965). Heat balance and the metabolic rate of new-born babies in relation to environmental temperature; and the effect of age and of weight on basal metabolic rate. Fournal of Physiology, 180, 239.

- and Robinson, D. C. (1968). Oxygen consumption in normally grown, small-for-dates and large-for-dates new-born infants. Fournal of Physiology, 199, 685.

Mestyán, J., Járai, I., Kekete, M., and Soltész, G. (1969). Specific dynamic action in premature infants kept at and below the neutral temperature. Pediatric Research, 3, 41.

Mount, L. E. (1963). Environmental temperature preferred by the young pig. Nature (London), 199, 1212.

Murlin, J. R., Conklin, R. E., and Marsh, M. E. (1925), Energy metabolism of normal new-born babies, with special reference to the influence of food and of crying. American fournal of Diseases of Children, 29, 1.

Oliver, T. K., Jr. (1965). Temperature regulation and heat production in the newborn. Pediatric Clinics of North America, $12,765$.

Scopes, J. W., and Ahmed, I. (1966). Minimal rates of oxygen consumption in sick and premature newborn infants. Archives of Disease in Childhood, 41, 407.

Silverman, W. A., and Agate, F. J., Jr. (1964). Variation in cold resistance among small newborn infants. Biologia Neonatorum 6, 113.

Correspondence to Dr. G. Katz, Department of Paediatrics, University College Hospital, Huntley Street, London W.C.1. 